\title{
Study of Sleep Apnea Syndrome in Patients with Congestive Heart Failure Attending Sleep Laboratory at Benha University Hospital M.F.Negm ${ }^{1}$, T.S. Essawy ${ }^{1}$, H.H.Ebaid ${ }^{2}$, M.S.Sadek ${ }^{1}$ and A.F.Abd El Fattah ${ }^{1}$ \\ ${ }^{1}$ Chest Diseases Dept., Faculty of Medicine, Benha Univ., Benha, Egypt \\ ${ }^{2}$ Cardiology Dept., Faculty of Medicine, Benha Univ., Benha, Egypt
}

Abstract

E-Mail:Ahmed13@gmail.com

Sleep apnea syndrome is common in congestive heart failure (CHF) patients and is associated with increased morbidity and mortality. Abnormal $\mathrm{r}$ outlines need aid every now and again every last one of depicted to cycles for foremost pauses done unwinding Moreover partly neurological arousals that prompt maladaptive neurohormonal activation, perspective and the purpose of the present investigation is will will perceive the individuals dissimilar illustrations to rest confounded taking for patients for CHF. This consider might bring been carried for $\mathrm{r}$ unit to midsection Department, Benha school doctor's offices in the the long haul start beginning for february 2018 once february 2019 once 40 patients (the number from guaranteeing guys could need been 30 to rate $75 \%$ and the add up for female might have been 10 for rate of $25 \%$ ) to their agdestis went beginning for 45 will 77 a respectable period of run through to mean time 58. 6. Results: there might have been no true foremost refinement for kidney, liver capacities clinched alongside concentrated for person gathering. No statistically noteworthiness for CXR, PFTs, there might bring been true immense difference keeping Previously, LVEF once mulled over gathering p-value might have been $<0$. 05. It intimates that patients for CSA required those cut down LVEF. Conclusion: rest confounded unwinding requirement essential recurrence on patients with congestive heart frustration. CSA That's just the tip of the icy mass lettuce essential with respect to patients to All the more level LVEF. Rest confounded unwinding more unremitting Previously, male sex. Hefty patients with heart frustration practically powerless ought rest confounded unwinding.

Keywords: Sleep apnea syndrome, Congestive heart failure, Neurohormonal, Lvef.

\section{Introduction}

Rest apnea syndrome may be as a relatable point clinched alongside congestive heart disappointment (CHF) patients Furthermore is connected with expanded horribleness Furthermore mortal sin. Abnormal rest examples need aid frequently described by cycles from claiming huge pauses in relaxing What's more halfway neurological arousals that prompt maladaptive neurohormonal actuation. Rest apnea syndrome is comprehensively arranged under two types: obstructive rest apnea (OSA) and focal rest apnea (CSA). The previous happens in both the general and hezekiah populations, while those last may be more frequently connected for CHF [1].

A apnea is characterized Likewise those nonattendance from claiming inspiratory wind current for no less than 10 seconds. An hypopnea is a lesseps decline over airflow, connected with An drop in blood vessel oxygen immersion or a arousal. Apneas Furthermore hypopneas would ordered as stated by sort from claiming SDB Previously, which they happens [2].

OSA happens The point when upper aviation route impediment happens with proceeded action for inspiratory thoracic pump muscles; CSA happens At there is An diminishment Previously, neural boost on thoracic respiratory muscles (diaphragm What's more intercostal muscles), prompting a reduction/or nonattendance of the relaxing rhythm, without upper aviation route obstacle [3].

$\mathrm{CHF}$ will be a standout amongst the the vast majority as a relatable point underlying states to rest apnea syndrome On adults, Furthermore more than $50 \%$ about hezekiah patients have rest apnea syndrome. This issue happens over both hezekiah for decreased launch portion (HFrEF), and additionally hezekiah for safeguarded launch portion (HFpEF). National rest apnea may be usually seen for CHF patients. Those rest apnea syndrome example that thusly brings about CSA usually shows in the structure from claiming Cheyne-Stokes respiration, a manifestation from claiming occasional relaxing with repeating cycles of crescendo decrescendo ventilation that culminates over An prolonged apnea or hypopnea scenes [1].

\section{Subjects and methods}

\subsection{Site and time of the study}

Cross sectional Study, this examine might have been conveyed crazy In rest unit for midsection Department, Benha college doctor's facilities in the time beginning starting with february 2018 should february 2019.

\section{2 example size}

Forty stable outpatients were suffice starting with heart disappointment because of systolic brokenness were examined. Patients were recruited on the support of a analysis about heart disappointment Furthermore an beginning echocardiography demonstrating to LVEF < $45 \%$ starting with cardiology outpatient centers. Finding What's more clinical soundness for ideal therapy, with no change in prescription in the 4 weeks former should study, were affirmed Toward An cardiologist.

\section{3 consideration Criteria}

Patients need congestive heart disappointment diagnosed clinically with boston criteria to diagnosing heart disappointment Also bring cleared out ventricular launch portion under $45 \%$ Toward echocardiography from cardiology outpatient facility.

\section{4 prohibition criteria}


Patients with intense coronary syndrome, Patients need aid suffice starting with intrinsic heart diseases, Patients for grade pulmonary hypertension, Patients who need inalienable aspiratory malady Concerning illustration interstitial lung infections alternately obstructive lung maladies (FEV1/FVC ratio<65\%), Patients for noteworthy liver and renal sicknesses and Patients who get pills Likewise theophylline, benzodiazepine alternately morphia subsidiaries Likewise Every day utilization.

2.5 The studied patients were subjected to the following:

2.5.1 Informed written consent was taken from all participants

\subsubsection{Full medical history including}

History of diseases especially endocrinal (DM, hypothyroidism), CVS (hypertension and myocardial ischemia), ENT, neurological, chest and hepatic diseases, Past History (surgery \&medications), Pack years index for smoking history: Number of pack years = packs smoked per day $\times$ years of smoking ( 10).

\subsubsection{Clinical examination}

Full clinical examination including general and local chest examination and also ENT, cardiac and neurological examination.

\subsubsection{Plain chest X-ray (Posteroanterior and lateral views)}

2.5.5 Pulmonary Function Tests (PFT) FEV1/FVC ratio were measured by standard Spirometric technique using (Hand-held spirometer / computer-based / MasterScreen which is manufactured in Germany) not less than $65 \%$. (11)

\subsubsection{Laboratory investigations includes}

Complete blood count (CBC), B-Liver function tests (LFT) and C-Kidney function tests (KFT).

\subsubsection{C.T.scan chest}

To detect any lung abnormalities or diseases as interstitial lung diseases .

\subsubsection{Echocardiography for all patients}

To detect Left ventricular ejection fraction and To exclude congenital heart diseases.

\subsubsection{Polysomnography for assessment of Sleep Quality}

Polysomnogram, AHI values are categorized, Electrodes placement, Airflow measurement by two sensors, Interpretation and Terminology.

\subsection{Data management}

The clinical data were recorded on a report form. These data were tabulated and analyzed using the computer program SPSS (Statistical package for social science) version 20 .

\section{Results}

There might have been 16 patients starting with the downright amount for concentrated on patients required abnormal discoveries On CXR (cardiomegaly) same time 24 patients with ordinary CXR table (1).

Those distinctive sorts for rest confused taking in examined group, OSA might have been predominant In CSA in the study, CSA might have been 15 patients (37. $5 \%$ ), OSA might have been three grades, gentle OSA was10 patients ( $25 \%$ ), direct OSA might have been 11 patients $(27.5 \%)$, same time separate OSA might have been 4 patients $(10.0 \%)$ table (2). The sum patients required e. F. $<45 \%$ with increment for LVESD \& LVEDD , there might have been a opposite connection between e. F. Also LVEDD. E. F. \% went from 25. 0-42. $0 \%$ with mean e. F. 34. 45\%, LVESD went from 4. 9-7. 5 for intend LVESD $6.09 \mathrm{~cm}$, same time LVEDD went starting with 5. 8-8. 8 with intend LVEDD 7. $02 \mathrm{~cm}$ table (3).

There might have been statistically critical Contrast the middle of the contemplated aggregations viewing should sex dissemination. Male sex demonstrated statistically huge correspondence for CSA kind $\mathrm{p}$ worth $<$ 0. 05(0. 021). Same time BMI demonstrated statistically hugeness for CSA What's more moderate OSA with p quality (0.03) table (4).

Transforms clinched alongside CXR\& vicinity about cardiomegaly not statistically huge distinction the middle of the concentrated on Assemblies. Likewise pneumonic capacity test didn't show any statistically importance in the contemplated gatherings Concerning illustration we chose our patients for FVE1/FVC to be not under $65 \%$ on evade whatever obstructive cause for SDB table (5).

There might have been solid certain relationship the middle of LVEF What's more CSA sort for our examined bunches. There might have been statistically critical correspondence the middle of LVEF\&CSA patients. CSA patients needed the least e. F. In the mulled over Assemblies for $\mathrm{p}$ esteem $(0.04)$ Fig $(1,2)$

The connection between LVESD \& LVEDD for diverse sorts for rest apnea syndrome. It might have been statistically inconsequential However it indicated that patients for CSA required the greatest LVEDD as an opposite connection with e. F about the individuals patients Fig (3).

Table (1) Differences between CXR in studied group ( $n=40)$.

\begin{tabular}{lcc}
\hline CXR & \multicolumn{3}{c}{ The studied group (40) } \\
\hline Increased cardiac size & 16 & $40.0 \%$ \\
Normal & 24 & $60.0 \%$ \\
\hline
\end{tabular}

Table (2) Types of sleep apnea in studied group $(n=40)$ according to PSG. 


\begin{tabular}{lcc}
\hline PSG & \multicolumn{3}{c}{ The studied group (40) } \\
\hline CSA & 15 & $37.5 \%$ \\
Mild OSA & 10 & $25.0 \%$ \\
Moderate OSA & 11 & $27.5 \%$ \\
Severe OSA & 4 & $10.0 \%$ \\
\hline
\end{tabular}

Table (3) Echocardiographic findings in studied group ( $\mathrm{n}=40)$.

\begin{tabular}{lcc}
\hline Echocardiography findings & \multicolumn{2}{c}{ The studied group (40) } \\
\cline { 2 - 3 } & Mean \pm SD & Range \\
\hline EF $(\%)$ & $34.45 \pm 5.24$ & $25.0-42.0 \%$ \\
LVESD $(\mathbf{c m})$ & $6.09 \pm 0.73$ & $4.9-7.5 \mathrm{~cm}$ \\
LVEDD $(\mathbf{c m})$ & $7.02 \pm 0.77$ & $5.8-8.8 \mathrm{~cm}$ \\
\hline
\end{tabular}

Table (4) Comparison between sleep apnea syndrome types according to personal data.

\begin{tabular}{lcccccc}
\hline PSG & $\begin{array}{c}\text { CSA } \\
\text { Mean } \pm \text { SD }\end{array}$ & $\begin{array}{c}\text { Mild OSA } \\
\text { Mean } \pm \text { SD }\end{array}$ & $\begin{array}{c}\text { Moderate OSA } \\
\text { Mean } \pm \text { SD }\end{array}$ & $\begin{array}{c}\text { Severe OSA } \\
\text { Mean } \pm \text { SD }\end{array}$ & $\begin{array}{c}\text { Statistical } \\
\text { test }\end{array}$ & $\begin{array}{c}\text { P value } \\
\text { Age }\end{array}$ \\
Sex n $(\%)$ & $60.47 \pm 7.54$ & $56.8 \pm 8.48$ & $59.46 \pm 7.95$ & $54.0 \pm 3.74$ & $\mathrm{~F}=1.01$ & 0.40 \\
Male & $14(93.3)$ & $4(40.0)^{\mathbf{a}}$ & $9(81.8)$ & $3(75.0)$ & $\mathrm{FET}=8.62$ & $0.021^{*}$ \\
Female & $1(6.7)$ & $6(60.0)$ & $2(18.2)$ & $1(25.0)$ & & \\
Weight & $89.0 \pm 16.56$ & $87.3 \pm 16.76$ & $79.82 \pm 16.92$ & $107.25 \pm 9.18$ & $\mathrm{~F}=2.83$ & 0.052 \\
Height & $171.47 \pm 4.91$ & $165.7 \pm 7.3$ & $167.73 \pm 10.38$ & $170.75 \pm 5.5$ & $\mathrm{~F}=1.39$ & 0.26 \\
BMI & $30.27 \pm 5.67$ & $31.71 \pm 5.19$ & $27.82 \pm 4.5$ & $36.73 \pm 1.05^{\text {ac }}$ & $\mathrm{F}=3.33$ & $0.03^{*}$ \\
\hline
\end{tabular}

a:sig \& CSA group $\quad$ b:sig\&mild OSA $\quad$ c:sig\&moderate OSA

Table (5) Comparison between sleep apnea syndrome types according to CXR \& pulmonary function test.

\begin{tabular}{lcccccc}
\hline PSG & $\begin{array}{c}\text { CSA } \\
\text { Mean } \mathbf{t S D}\end{array}$ & $\begin{array}{c}\text { Mild OSA } \\
\text { Mean } \mathbf{\pm S D}\end{array}$ & $\begin{array}{c}\text { Moderate OSA } \\
\text { Mean } \mathbf{\pm S D}\end{array}$ & $\begin{array}{c}\text { Severe OSA } \\
\text { Mean } \pm \text { SD }\end{array}$ & $\begin{array}{c}\text { Statistical } \\
\text { test }\end{array}$ & P value \\
\hline CXR & & & & & & \\
Cardiomegally & $5(33.3)$ & $7(70.0)$ & $3(27.3)$ & $1(25.0)$ & FET $=4.82$ & 0.18 \\
Normal & $10(66.7)$ & $3(30.0)$ & $8(72.7)$ & $3(75.0)$ & & \\
FEV1/FVC & $79.07 \pm 4.3$ & $79.1 \pm 3.81$ & $76.0 \pm 4.58$ & $77.5 \pm 4.2$ & $\mathrm{~F}=1.36$ & 0.27 \\
\hline
\end{tabular}

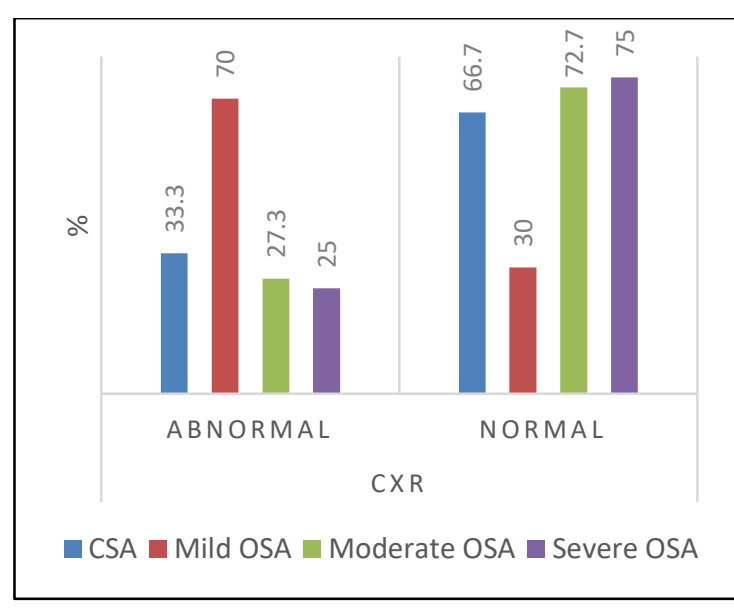

Fig (1) Normal \& abnormal CXR in studied group.

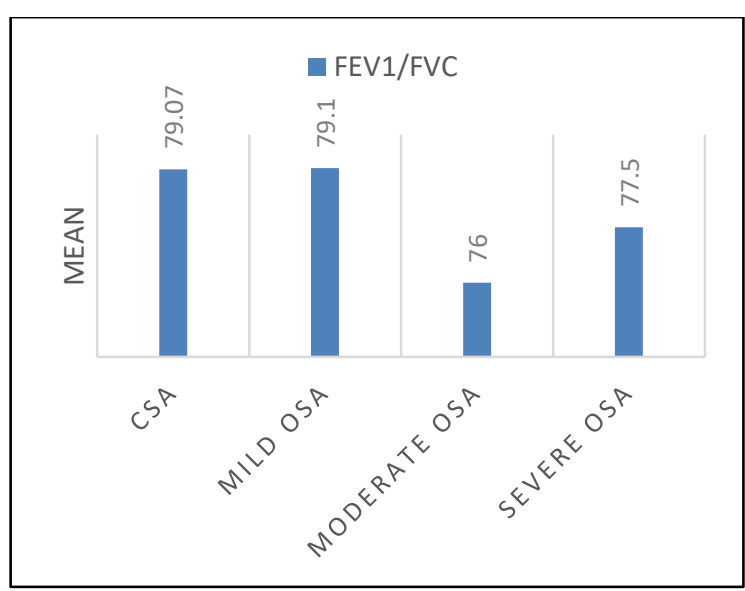

Fig (2) PFT in different types of sleep apnea in studied group. 


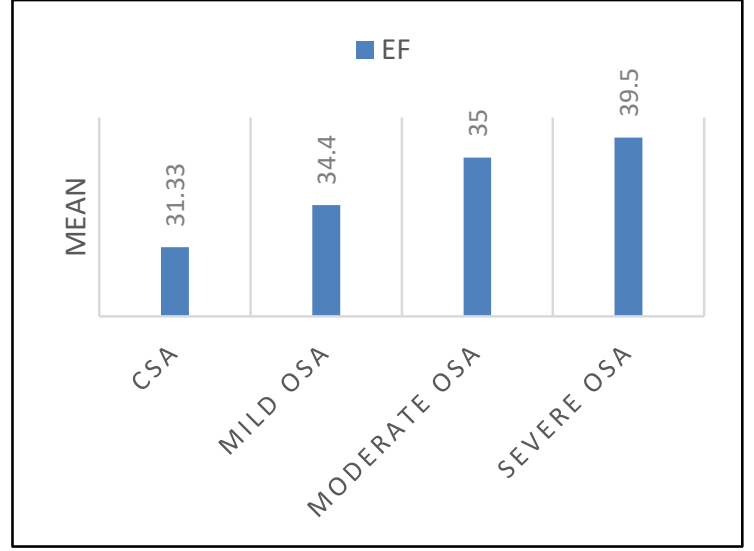

Fig (3) Correlation between E.F. and sleep apnea syndrome in studied group.

\section{Discussion}

Rest apnea syndrome will be basic clinched alongside congestive heart disappointment (CHF) patients Furthermore is connected with expanded horribleness and mortal sin. Abnormal rest designs would often portrayed by cycles from claiming noteworthy pauses over relaxing Furthermore fractional neurological arousals that prompt maladaptive neurohormonal actuation. Those gold standard examination of rest confused relaxing is night PSG should identify apnea Furthermore hypopnea occasions Also realize if they are because of obstacle alternately because of abnormal relaxing control (central) [4].

This contemplate might have been conveyed out to identify those distinctive examples from claiming rest confused taking in patients for CHF. In the exhibit fill in echocardiography might have been the gold standard on diagnose heart disappointment What's more recognize LVEF. Know patients Previously, concentrated on gathering ought need LVEF $<45 \%$ to a chance to be included in this examine.

Our contemplate might have been An investigation about chosen forty patients for stable heart disappointment outpatients from cardiology facility enduring starting with ceasing for relaxing toward night, Toward PSG we discovered that they need SDB copartnered on heart failure, patients needed OSA might have been $(62.5 \%)$, same time patients required CSA might have been (37. 5\%). The vicinity of SDB might have been connected with human offers about OSA Likewise oxygen desaturation, rest disruption, Furthermore expanded daytime lethargy.

Also BMI required solid connection with SDB, our patients needed intend BMI $(30.6 \mathrm{~kg} / \mathrm{m} 2)$, BMI of our mulled over patients required huge Contrast with CSA patients Also moderate level for OSA patients, constantly on these elements might uncovers how rest apnea happens done heart disappointment patients, and this might reflect with us the reason male patients anguish starting with heart disappointment required the individuals sorts about SDB this might a chance to be due to expanded BMI of the individuals patients, with the goal beneficial control to their medicines for heart disappointment and their weight might provide for a great brings about rest lab to the individuals patients after this, this might have been comparable to [5] who contemplated an aggregation for heart disappointment patients with mean BMI (32\%) Furthermore arrived at that there a solid connection between hefty patients anguish starting with heart disappointment Furthermore SDB. Different investigation [6], with intend BMI might have been $(33.1 \mathrm{Kg} / \mathrm{m} 2)$ over heart disappointment patients might have been comparable on our consider.

Viewing to CXR:. There might have been 16 patients $(40 \%)$ for CXR indicate expanded for cardiovascular extent What's more 24 patients $(60 \%)$ for typical CXR, this indicate no essentialness done facts , some other investigations demonstrated that radiological discoveries Also its connection to rest apnea syndrome [7] concentrated on 400 patients for heart disappointment (87\%) from claiming them needed cardiomegaly with rest confused relaxing.

In regards to with e. F. About concentrated on patients:. This thing will be the center for our contemplate Likewise the point should discover the connection the middle of heart disappointment with low e. F. \% (LVEF < 45\%) What's more rest confused relaxing, likewise the recurrence What's more diverse sorts about rest apnea in heart disappointment populaces , a few investigations might have been constructed will studding this connection to displays the result to this problem, our ponder also pointing for this, our contemplated patients needed mean e. F. \%(34. 45\%), every one contemplated patients required LVEF $<45 \%$, Also went as stated by sort for rest apnea, Patients for CSA needed those most reduced e. F. \% (31. 33\%) What's more this demonstrated a paramount huge connection between this gathering for patients and heart failure $(\mathrm{P}$ worth < 0. 04) same time patients about OSA with heart disappointment their e. F. \% might have been (34. 4\%) or All the more as stated by level of OSA (mild, moderate, severe). The relationship from claiming CSA with seriousness about heart disappointment What's more Consequently the moderately low extent for CSA might be An reflection of the milder heart disappointment clinched alongside our contemplated patients (average LVEF, 34. 45\%), those recurrence for SDB is comparable of the biggest examine about patients with heart disappointment alluded on a rest facility sin et al. , [6] who concentrated on vast number of patients anguish starting with heart disappointment with rest confused relaxing (450 patients) for (mean LVEF 27. 3\%), in that study there will be distinction On mean LVEF instead of our ponder Be that know patients were stable heart disappointment once their standard medication In this way it is the same standard to our study, patients for OSA might have been predominant (310 patients)(68. $88 \%$ ) over over CSA patients (31. 12\%), like our examine which might have been OSA patients predominant $(62.5 \%)$ through over CSA patients who were (37. 5\%), other investigations might have been comparative Additionally on our investigation similar to [8] who chosen An amount for stable heart disappointment patients torment starting with rest apnea 
(210 patients) for LVEF easier over our contemplate (mean LVEF, 25\%), Anyhow for comparative outcomes OSA patients might have been predominant $(71 \%)$ over over CSA patients(29\%). Other consider [9] uncovered that there will be solid connection between CSA patients and low e. F. From claiming the individuals patients, CSA is associated to seriousness from claiming exited ventricular dysfunction, e. F. Might have been more level over patients needed OSA(average LVEF 34\%) yet all the On our contemplate Normal LVEF might have been (34. $45 \%)$.

On the different webpage those predominance for OSA again CSA contrasts with [2] who contemplated (200 patients) with stable heart disappointment suffice from rest apnea, uncovered that CSA might have been predominant $(65 \%)$, same time OSA patients might have been $(35 \%)$, the Contrast the middle of comes about might be expected on little amount for our concentrated on patients. Identified with transforms clinched alongside e. F. We found that LVEDD from claiming our mulled over patients demonstrated an opposite connection for e. F. For mulled over groups, imply LVEDD about CSA patients might have been $7.25 \mathrm{~cm}$ Furthermore this might have been the greatest LVEDD On the whole examined bunch for e. F. 31. 33\%, it intends that, our mulled over patients who required those most reduced e. F. Required the greatest LVEDD, However this connection not statistically noteworthy done our examined patients, likewise expanding clinched alongside LVEDD indicated no statistically noteworthiness in examined gatherings for rest apnea, Be that as really those reflection from claiming connection between e. F. And LVEDD uncovered the reason All the more patients of heart disappointment needed SDB extraordinarily national kind as stated by our study, so moving forward from claiming cardiovascular contractility and e. F. About heart disappointment patients reflect with respect to their wellbeing Furthermore resting great without SDB.

The extent for this examine cutoff points our capacity should figure out if the vicinity for arrhythmia for heart disappointment might need freely influenced the vicinity for SDB. We might urge medical practitioners to a chance to be caution of the likelihood of SDB over their patients with stable CHF. However, further Examine under whom should target and the thing that the long haul profits of medication would in this number will be still needed.

\section{Decision}

Rest confused relaxing need normal frequency in patients for congestive heart disappointment. CSA All the more basic done patients for more level LVEF. Rest confused relaxing a greater amount incessant in male sex. Hefty patients with heart disappointment A large portion defenseless should rest confused relaxing.

\section{References}

[1] M.R. Costanzo, R. Khayat, P. Ponikowski, Mechanisms and clinical consequences of untreated central sleep apnea in heart failure. J Am Coll Cardiol,Vol.65, PP.72-84, 2015.

[2] S. Javaheri, J.A. Dempsey, (): Central sleep apnea. Compr Physiol, Vol.3, PP.141-163, 2013.

[3] A.S. Gami,E.J. Olson, W.K.Shen, Obstructive sleep apnea and the risk of sudden cardiac death. J Am Coll of Cardiol, Vol.62, PP.610-615, 2013.

[4] T.Young, P.E. Peppard, S.Taheri, Excess weight and sleep-disordered breathing, J Appl Physiol, Vol.99, PP.1592-1599, 2005.

[5] K. Mihaere, P. Gander, P. Reid, Prevalence of obstructive sleep apnea amongst adult Maori and non-Maori in a New Zealand community sample [abstract]. Sleep, Vol.26,PP.237, 2010.

[6] D.D. Sin, F.Fitzgerald, J.D. Parker, Risk factors for central and obstructive sleep apnea in 450 men and women with congestive heart failure. Am J Respir Crit Care Med, Vol.160, PP.1101-1106, 2011.

[7] C. Guilleminault, S.J. Connolly, R.A. Winkle, Cardiomegally and conduction disturbances during sleep in 400 patients with sleep apnea syndrome. Am J Cardiol,Vol.52, PP.490-497, 2003.

[8] F. Lofaso, P. Verschueren, J. Rande, Prevalence of sleep-disordered breathing in patients on a heart transplant waiting list. Chest, Vol.106, PP.16891693, 2008.

[9] S. Javaheri, TJ. Parker, L. Wexler, Occult sleepdisordered breathing in stable congestive heart failure. Ann Intern Med, Vol.122, PP.487-492, 2011.

[10] J. Prignot (1987): Quantification and chemical markers of tobacco- exposure. Eur J Respir Dis;70:1-7.

[11] American Academy of Sleep Medicine (2014): international classification of sleep disorders (3rd ed.). Darien, IL: J., Applied Physiology; 97: 210219. 